after violent convulsions. In 1828, the wife $/$ or, what is more probable, he fell over of of a man who had died in Guy's Hospital of himself, from the vital energies becoming hydrothorax, begged that the stomach might paralysed, in consequence of the hrmor. be examined, for that her husband had rhage which must have been going on, at this taken, some years before, nux vomica, moment of time, within the head. Eviwhich had produced symptoms which had dence, it is true, went to establish what been mistaken for hydrophobia; no traces, might have been, and perhaps was the however, of any previous inflammation were fact, that both during, and subsequent to, perceptible.

\title{
TRIAL FOR MANSLAUGHTER.
}

ORGANIC DISEASE OF THE HFART, APOPLEXY, AND SOFTENING OF THE BRAIN.

\section{To the Editor of The LANCET.}

SIR :-In one of Professor Thomson's excellent Lectures (Lect. $\mathrm{xxx}$., p. 183), which are now in the course of publication in TuE LA NCET, there occurs the following passage : - A person in a fit of passion, is pushed down, and dies suddenly; on opening the body, no blood is found effused in the pericardium, but there is an unsual enlargement and thickening in the muscular substance of the heart, and much blood is found effused in the brain. This might, erroneously, be ascribed to the fall; whereas it is more likely to have arisen from the impetus impressed on the blood by such a state of the heart, during the excitement of anger, being greater than the resistance of the vessels of the brain can sustain. *** In such a case, the person who caused the fall which preceded death, must be held guiltless."

In corroboration of this position of the learned and highly-talented Professor, as also with the view of combatting an opinion entertained by the medical gentleman who, in conjunction with me, examined the body after death, I beg leave to place on record, in the pages of this very ably-conducted and widely-circulated periodical, the following

CASE.-About three months since, a quarrel originated between a party of men in this town, in which one of the belligerents, unfortunately, met his end. The facts of the occurrence, as elicited in evidence on the trial, at the county (Antrim) assizes, may be very briefly related. They are nearly as follows:-A verbal dispute, respecting some matters of trivial moment, arose between the deceased, whose name was Orr, accompanied with a comrade, on the one side, and a party of individuals, which counted five in number, on the other. Blows with the fist, as is usual in such cases, speedily followed, and Orr, after first prostrating one of the antagonist party, was himself, in turn, prostrated also. Whilst attempting, however, to regain his feet, and at about the moment when he had so far succeeded as to have obtained the semilunar posture, he was (for the evidence on this point was but imperfect) either again knocked down, strokes, from more or fewer of his adver. saries, with both liands and feet; still, the work of destruction had, most probably, commenced before this, and was, in all like. lihood, at this instant of time nearly com pleted. Be this as it may, he died alnost instantaneously, and a verdict of "Man. slaughter" was returned against three ont of the four individuals, who were taken in. to custody. The penalty, owing to the pre. vious rather long confinement in gaol, was the mitigated one of a few months' impri. sonment.

\section{Autopsy, forty hour's after Death.}

The body was but slightly rigid, and there were observed two or three small dis. coloured spots on the superior part of the chest, and another, a rather lar'ger onc, upon the left temple. The vessels of the scalp were unusually distended with fluid blood, and there was found an effusion of this vital fluid, to the amount of about four ounces, at the base of the brain. No fractnie $e x$ isted in any of the bones of the head; nor did the substance of the brain present any, the least, unusual vascularity. It may be here remarked, that the vessel or vessels from which the hamorrhage proceeded could not, on examination, be detected. In the chest, on its right side, there existed an ex. tensive adhesion of the opposing pleurx, of an apparently rather old stauding, together with an effusion, into its cavity, of about half a pint of bloody serum. On opening the pericardium, the heart, which was ge. nerally enlarged, was found to fill, pretty accurately, this membraneous capsule. A section of this organ displayed a considera. ble hypertrophy, or general thickening, in the muscular substance of both the ventri. cles, but more especially the left one. This latter carity was also slightly dilated. The liver generally, but particularly its left lobe, was greatly enlarged, but normal, alike in colour and consistence. It should have previously been mentioned, that the blood in the body generally preserved its perfect fluidity.

It is here quite evident, that the fatal re. sult was immediately attributable to the large extravasation of blood at the base of the brain, a species of lesion which has been very appropriately termed, by the philoso. phic M. Serres, meningeal apoplexy. But whence the cause, or concatenation of causes, if such there really were, which de. termined the meningeal hæmorrhage? Ea. 
sily replied to as the question here proposed may be, from a bare reference to the greatly diseased condition of the heart, yet the gentleman to whom $I$ have above alluded, strange as it may appear, entertained the, I must say, very shallow idea, that the hrmorrhage in question was "the effect of blows or falls inflicted on the head." An opinion formed such as this, without taking into account the surely not unimportant influence, referable to the organic cardiac disease, -an influence which must, under the high excitement of anger and great muscular action, have been called, at the moment, into very powerful operation, -was, I submit, wholly unsupported by the pathological facts revealed on the postmorteminspection; and, under other circumstances, where the provocations given on the part of the deceased, together with his entire willingness to end the dispute by another immediate recourse to physical force, could not have been so clearly established, by as equally direct and respertable testimony, it most likely would, per se, have placed the prisoners in a rather serious position.

In my evidence on the inquest (as, for some reason with which $I$ am not, at present, acquainted, I was not afterwards called on, by a superior court, either for its confirmation, or if necessary, upon ulterior reflection, its modification), I took the liberty of dissenting, in toto, from this opinion, and I did so chiefly from the very cogent reason, that it entirely excluded, without the least allusion to, an important, if, indeed, not the sole, link in the chain of causation. I allude to the intimate connection which has been discovered to exist between hypertrophy of the left ventricle of the heart and apoplexy, whether cerebral or meningeal. Indeed, the relationship between these two, as cause and effect, has been justly viewed by a distinguished modern writer(Dr. Hope), as one of the best established doctrines in modern pathology. The observations, too, of Drs. Macartmey, Alison, and Mackintosh, with, in fact, all our best pathologists, which observations are, it will not be disputed, well embodied in the above hypothetical fact of Dr. Thomson's, - all go to confirm this most important position. Hence, in the case just detailed, the leaving wholly out of account this, to say the least, very influential item in the category of causes, which induced the fatal hromorrhage, must appear to every candid mind, as a singular oversight on the part of my medical friend, for which, it must be confessed, I cannot at all account; and in thus laying this statement of facts, relating to it, before the profession, I beg it to be distinctly understood, that, as a humble but ardent admirer of scientific truth, $I$ am influenced by no other motive than a sincere regard for the cause of justice, so that, in cases of a similar nature, which, it may be safely presumed, are not uncommon, the medical peactitioner, whilst accurately balancing the exact amount of importance which may attach to each particular cause respectively, in operating a fatal result, will not, as in the present instance, culpably overlook this highly interesting relationship between organic disease of the heart, and apoplexy, and softening of the brain; but, when the former affection is present, will attach to it all the importance to which it may be legitimately entitled. I am, Sir, your very obedient and much obliged serrant,

\section{Lisburn, August 18th, 1837.}

$$
\text { J. Joinston Keaso, M.D. }
$$

CASES HLLUSTRATTE OF THE

\section{TREATMENT OF FEVER \\ BY}

SALINE MEDICINES.

By C. R. Bree, Esq., M.R.C.S.

In The Lancet of Uctober 1st, 1836, I inserted three cases illustratlve of the effects of the administration of saline medicines in morbid conditions of the blood. Since tlat time I have followed a similar line of practice in numerous cases, where $I$ had reason to fear an actual or a threatened deterioration of the vital fluid. The able experiments of Dr. Stevens have proved that in fevers of a congestive character there is a deficiency of the saline constituents of the blood, and from this fact we may fairly assume that there is a disposition to this change in fevers of a milder form; and, hence, we may form a rational prophylactic mode of treating these diseases.

There can be no doubt about the useful. ness of saline medicines in fever. Few cases are ever treated without them; but it was not until the work of $D 1^{\circ}$. Stevens was published, and the powerful aid of chemistry in modern days directed attention to the alterations produced by disease in the constituents of the blood, that their modus operandi was clearly understood. It is not im. probable that many lives are saved by saline medicines, in the treatment of simple fever. We all know the tendency which fever of the mildest form has to assume a typhoid character, and we have every reason for inferring that we prevent this by imbuing the system with saline matter, a deficiency of which, as is exemplified in Asiatic cholera and congestive fever, is incompatible with existence.

It is impossible, however, to lay down any fixed rules for the treatment of fever. An improved system of therapeutics has shown that diseases of all kinds must be treated, not according to the name they bear, but in 